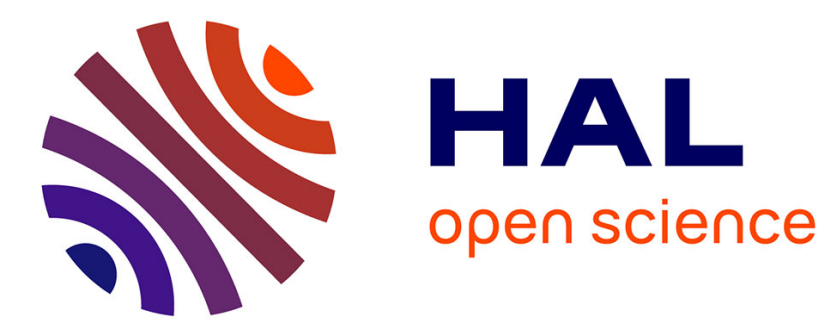

\title{
Compaction behavior of binary mixtures
}

\author{
Abderrahim Michrafy, Harona Diarra, John A. Dodds
}

\section{To cite this version:}

Abderrahim Michrafy, Harona Diarra, John A. Dodds. Compaction behavior of binary mixtures. Powder Technology, 2009, 190 (1-2), pp.146-151. 10.1016/j.powtec.2008.04.066 . hal-01680756

\section{HAL Id: hal-01680756 https://hal.science/hal-01680756}

Submitted on 7 Nov 2019

HAL is a multi-disciplinary open access archive for the deposit and dissemination of scientific research documents, whether they are published or not. The documents may come from teaching and research institutions in France or abroad, or from public or private research centers.
L'archive ouverte pluridisciplinaire HAL, est destinée au dépôt et à la diffusion de documents scientifiques de niveau recherche, publiés ou non, émanant des établissements d'enseignement et de recherche français ou étrangers, des laboratoires publics ou privés. 


\title{
Compaction behavior of binary mixtures
}

\author{
A. Michrafy *, H. Diarra, J.A. Dodds \\ RAPSODEE (UMR CNRS 2392), Ecole des Mines d'Albi-Carmaux, Campus Jarlard, 81000 Albi, France
}

\begin{abstract}
A B S T R A C T
The compaction behavior of binary mixtures of lactose and a functional excipient containing $98 \%$ of microcrystalline cellulose and $2 \%$ of silica was investigated by experiment. The densification process and the role of each component in the compaction behavior were examined by analyzing the effect of the composition on the stress transmission to the powder bed in axial (stress transmission) and in radial (stress transfer) directions. Unlike the behavior of a single component where the applied pressure is predominantly transmitted in the axial direction to the powder bed for densification, the increase of the composition of lactose up to $50 \%$ in mixtures increases the stress transfer that becomes greater than the stress transmission. However, for the compaction behavior of mixtures with $50 \%$ of lactose, two opposite behaviors were found, below and above a pressure around $70 \mathrm{MPa}$. Die-wall friction showed also a change at this pressure due to a smoothed contact surface with wall. By increasing the composition of lactose $(>50 \%)$, the behavior of mixtures becomes dominated by the behavior of lactose where the transmission is better than the transfer. This study demonstrates that the analysis of the compaction behavior of mixtures by recording stress transmission, stress transfer and wall friction give pertinent information about the role of each component in the densification and could be, to a certain extent, help to the selection of excipient for powder formulation.
\end{abstract}

\author{
Keywords: \\ Die-compaction \\ Binary mixtures \\ Densification \\ Radial stress \\ Friction \\ Capping
}

\section{Introduction}

The die-compaction is a size enlargement process for particulate solids to produce tablets with sufficient strength for storage and handling. This process which is economic and ensures a good stability for tablets, is widely used in pharmaceutical industry. Pharmaceutical tablets are often manufactured from several powders and it is of interest to analyze the tablet properties according to the formulation. In the field of the compaction of binary mixtures, several recently studies were reported in the literature and concerned properties of the tablets such as the evolution of compacted binary mixture porosity [1], the solubility [2], the tensile strength [3-5], or the compressibility of the mixtures [6]. However, the role of each component in the densification process and in the capping problem of tablets was not considered.

The present paper reports on the densification behavior of binary mixed powders of lactose and a functional excipient containing $98 \%$ of microcrystalline cellulose and $2 \%$ of silica during die-compaction according to the components. The goal is to propose an analysis based on wall friction and stress transmission in axial and radial directions to investigate the behavior of each component in the mixture during the compaction.

\footnotetext{
* Corresponding author. Tel.: +33 56349 3162; fax: +33 563493025. E-mail address: michrafy@enstimac.fr (A. Michrafy).
}

\section{Materials and Methods}

\subsection{Instrumented press}

\subsubsection{Instrumentation}

The apparatus used for the compaction was a reciprocating tablet press (Frogerais OA). The pressure is applied with the upper punch and the ejection with the lower one. The upper and the lower punches are instrumented by strain gauges measuring pressures and by LVDT sensor for the relative displacement between punches. A fixed cylindrical die of $11.28 \mathrm{~mm}$ of diameter and $10 \mathrm{~mm}$ of height was modified as shown in Fig. 1 and was equipped with a strain gauge (Wheatstone bridge circuit) mounted on the die wall. The gauge was placed at $1.5 \mathrm{~mm}$ from the surface of the lower punch so that at end of the compaction, the gauge is approximately positioned at the middle of tablets with height in the range 3-4 mm.

The geometry of the die allows the increasing of the sensitivity of the system. Also, this system offered the advantage of not altering the sensor as in the instrumentation with load cell in contact with the powders (particularly the fine and cohesive powders).

\subsubsection{Calibration of radial gauge}

A rubbery material was chosen for the calibration because it behaves as very nearly hydrostatically under pressure. Thin discs of $1 \mathrm{~mm}$ thickness and $11.28 \mathrm{~mm}$ diameter were cut from rubber material using a concave punch (for its cutting capability). As the height of the chamber of the die is as $10 \mathrm{~mm}$, five curves (pressure in 

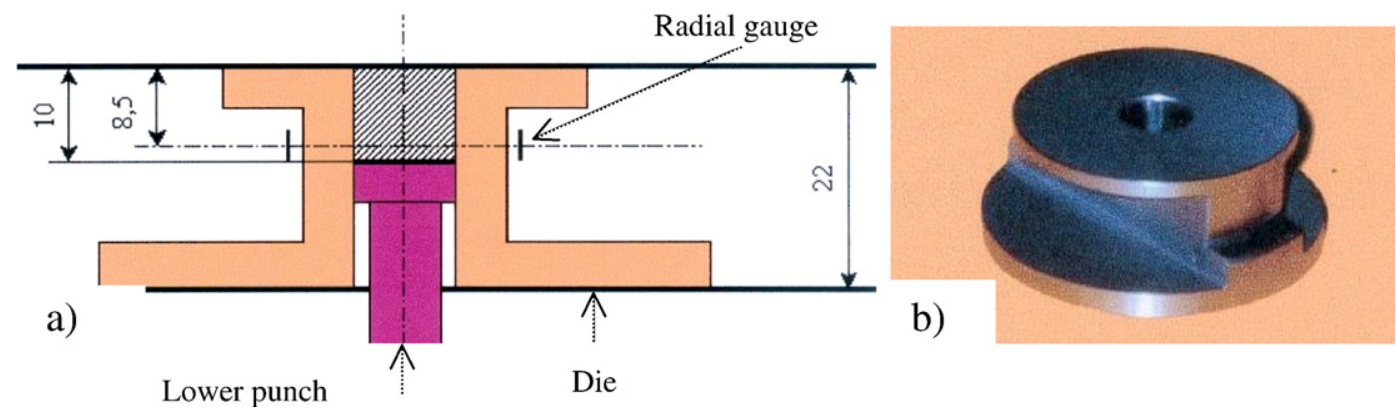

Fig. 1. (a) Schematic drawing of instrumented die, dimension in $\mathrm{mm}$, (b) picture of modified die.

MPa vs signal in $\mathrm{mV}$ ) were generated according to the height of stacked discs. Each curve was generated from 20 data measurements. The generated curves corresponding to heights $2,4,6,8$ and $10 \mathrm{~mm}$ were linear and their slopes were determined for the conversion of the signal of radial gauge in $\mathrm{mV}$ to a pressure in MPa. It should be noted that the maximum applied pressure was limited to $120 \mathrm{MPa}$ to avoid the creep problem of thin discs. For a given height of tablet, the radial pressure was obtained by interpolating data from the calibration curves.

\subsection{Binary mixtures preparation}

Two powders used as excipients in the pharmaceutical formulations were selected for the binary mixtures: a lactose powder (lactose Granulac® 140 from Meggle GMBH) and a functional excipient noted 'smcc' containing microcrystalline cellulose 98\% and silica 2\% (Prosolv ${ }^{\circledR} 90$ from J. Rettenmaier \& Shöne) [7]. The lactose is known for its fragmentary behavior with compression and its bad flow, whereas the powder 'smcc' behaves like microcrystalline cellulose (plastic behavior) and has a good flow. A Scanning Electron Microscopy image of these powders is presented in Fig. 2 and shows the rough surface of smcc. This suggests favorable contact conditions of particles. The basic characteristics (average size of particles, true density and bulk density) of the studied powders are summarized in the Table 1.

Various mass fractions $(15,25,35,50,60$ and $75 \%$ of lactose in mass) in lots of $100 \mathrm{~g}$ were blended and were thoroughly mixed in a Turbula mixer (Turbula ${ }^{\circledR}$, System Schatz, Basel Switzeland) during 5 min with $32 \mathrm{rpm}$.

\subsection{Compaction of mixtures}

Cylindrical flat tablets have been made from these powders by the following procedure. $100 \mathrm{~g}$ lots of mixtures were put in the hopper of the reciprocating press just after the mixing operation. During the compaction process, a mass of $0.45 \pm 0.02 \mathrm{~g}$ of powder was poured in the die and compacted at different pressures using the instrumented reciprocating tablet press making it possible to record the pressure and displacement on the top and the bottom punches as well as the radial stress on the die. The compaction was made at the speed around $31 \mathrm{~mm} / \mathrm{s}$ at the ambient temperature of $25{ }^{\circ} \mathrm{C} \pm 1{ }^{\circ} \mathrm{C}$ and $64 \%$ of relative humidity. Once the tablet was ejected, its mass was measured with an electronic balance (CP 224S, Sartorius Germany). For each pressure, six compacts were made using the above procedure. To avoid die filling problems at the start of compaction run, only the last three compacts were considered in measurements. Each measurement presented here was the mean of the characteristics of three tablets. The maximum errors on pressures depended on the proportion of lactose in mixtures. For lactose composition lower $50 \%$, maximum of errors were as $2.8 \%$ for applied pressure, $0.4 \%$ for transmitted pressure and $2.9 \%$ for radial pressure. For composition greater than $50 \%$ of lactose, errors were as
3.4\% for applied pressure, $0.5 \%$ for transmitted pressure and $4.1 \%$ for radial pressure.

\subsection{Stress transmission and stress transfer ratios}

During die-compaction of a powder mass, the axial stress applied by the upper punch is transmitted to the powder causing its densification in axial direction whereas a stress is developed in die cavity by expansion in normal direction to die wall and measures the densification in radial direction. The stress transmitted to the lower punch is sensed and is less than the applied pressure because the existence of an opposite stress on the powder bed due to wall friction. The capacity of a powder mass to convert the applied pressure to the axial and radial densification is a characteristic of the behavior of the

a)

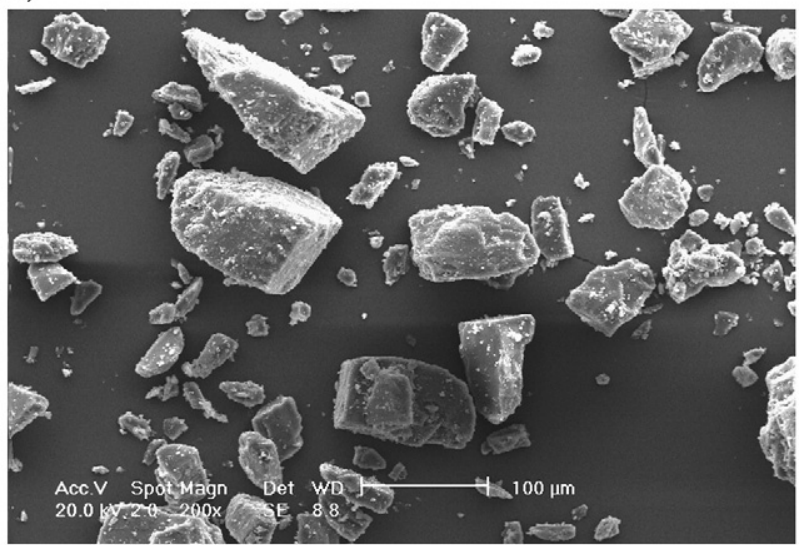

b)

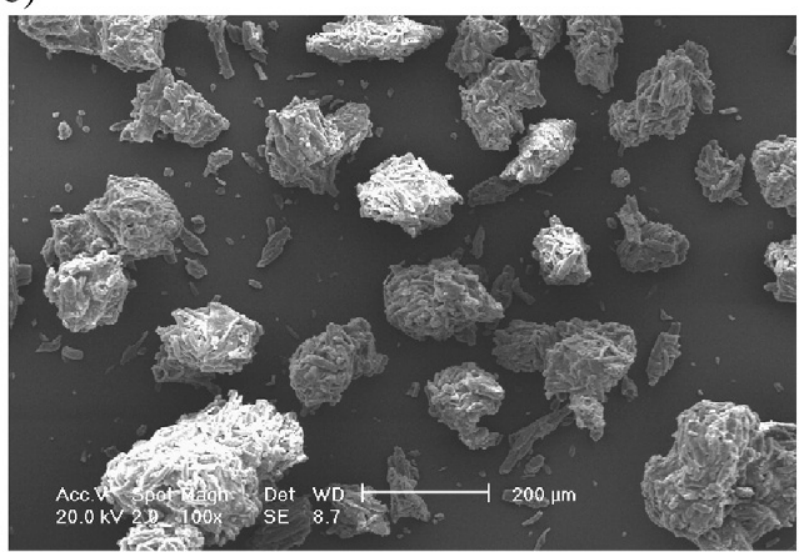

Fig. 2. Scanning Electron Microscopy images of powders (a) lactose Granulac 140 (Meggle Gmbh) and (b) Prosolv ${ }^{\circledR} 90$ (J. Rettenmaier \& Shöne). 
Table 1

Basic characteristics of lactose and smcc

\begin{tabular}{llll}
\hline Powders & $d_{50}(\mu \mathrm{m})$ & Apparent density $\left(\mathrm{g} / \mathrm{cm}^{3}\right)$ & True density $\left(\mathrm{g} / \mathrm{cm}^{3}\right)$ \\
\hline smcc & 90 & 0.32 & $1.598 \pm 0.003$ \\
lactose & 70 & 0.66 & $1.561 \pm 0.0022$ \\
\hline
\end{tabular}

a)

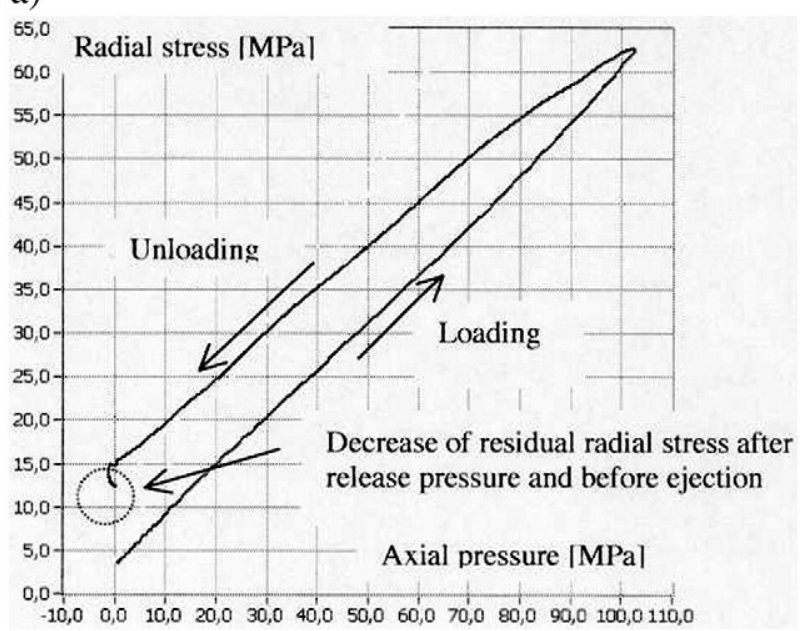

b)

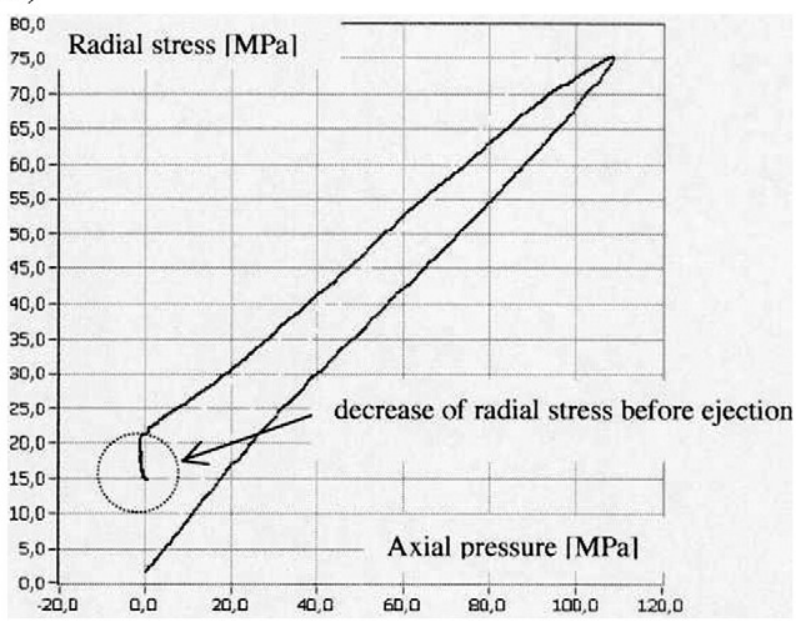

c)

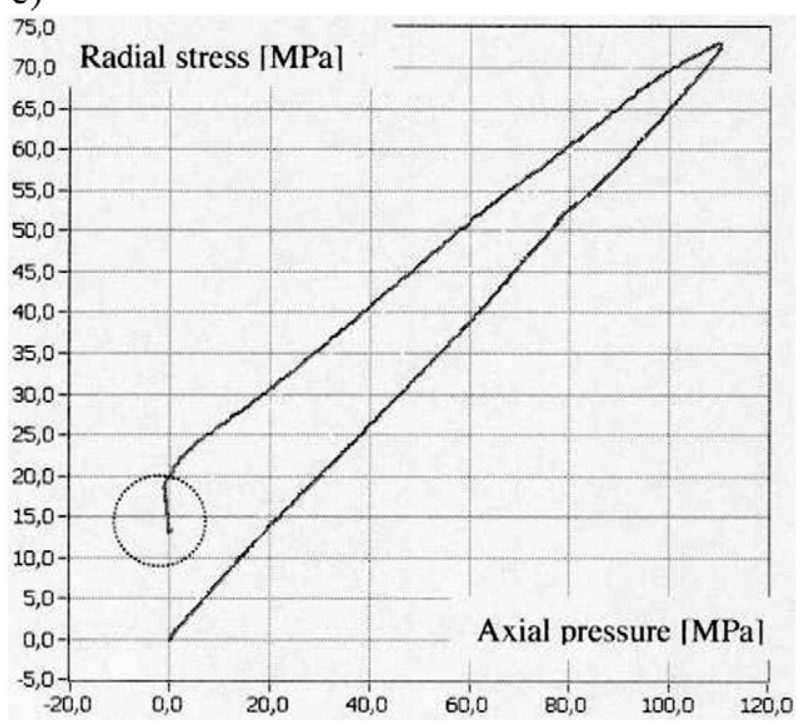

Table 2

Restituted residual radial stress (RRS) versus composition of lactose (binary mixtures smcc+lactose)

\begin{tabular}{lllll}
\hline Lactose\% & $\sigma_{\mathrm{u}}[\mathrm{MPa}]$ & $\sigma_{\mathrm{r}, 1}[\mathrm{MPa}]$ & $\sigma_{\mathrm{r}, 1}[\mathrm{MPa}]$ & RRS $(\%)$ \\
\hline 15 & 115 & 17.5 & 14.5 & 2.6 \\
25 & 127 & 18 & 15.5 & 1.97 \\
35 & 112 & 17.6 & 14.7 & 2.59 \\
50 & 116 & 22 & 15.5 & 5.60 \\
65 & 94 & 16.1 & 11.7 & 4.68 \\
75 & 111 & 19 & 13 & 5.40 \\
\hline
\end{tabular}

powder. In this way Shaxby and Evans [8] introduced the ratio of transmitted to applied pressure as a logarithmic relationship of thickness, diameter of the tablet and a material constant. In the work of Unckel [9] and Toor et al. [10] the ratio of radial to axial pressure was included in the above relationship.

In this study, the stress transmission and transfer defined as:

Transmission $=\sigma_{\mathrm{l}} / \sigma_{\mathrm{u}}$

and the stress transfer expressed as

Transfer $=\sigma_{\mathrm{r}} / \sigma_{\mathrm{u}}$

were used as indices quantifying capabilities of mixtures to favor axial transmission or radial transfer during the compaction cycle. They were also used as tools to analyze mechanisms of the densification and the anisotropy of the stress transmission generated in the powder bed.

\subsection{Residual radial stress and capping analysis}

The radial to axial pressure of the compaction cycle has been studied by different authors [11-13]. They show the interest of the analysis of the profile of radial to axial pressure in the characterization of the compaction properties of powders and the analysis of lamination and capping problems. In the context of this study, the profile of the radial to axial pressure in cycle compression was analyzed according to the composition of binary tablets. From experimental data, it was found that the residual radial stress could not explain capping observed for compositions of lactose higher than $50 \%$. It was however suggested examining the decrease of radial stress when the axial pressure reached zero $\left(\sigma_{\mathrm{r}, 1}\right)$ and just before starting the ejection $\left(\sigma_{\mathrm{r}, 2}\right)$. During this period, the tablet is yielding continuously in shear and its magnitude (relatively to the pressure) was expressed as:

$\mathrm{RRS}=\left(\sigma_{\mathrm{r}, 1}-\sigma_{r, 2}\right) / \sigma_{\mathrm{u}}$

The ratio RRS as "Restituted Radial Stress" has been used to analyze the capping according to composition.

\subsection{Die-wall friction}

The friction between the mixtures and die wall was examined to explain the behavior of certain compositions. Coulomb friction was assumed at die wall, i.e. the friction traction was assumed proportional to the traction at normal direction to the die wall. The friction coefficient $\mu\left(\sigma_{\mathrm{r}}\right)$ was evaluated from radial pressure $\sigma_{\mathrm{r}}$ and pressures on the upper $\sigma_{\mathrm{u}}$ and the lower $\sigma_{1}$ punches at end of the compaction (maximum pressure) as:

$\mu\left(\sigma_{\mathrm{r}}\right) \approx\left(\sigma_{u}-\sigma_{l}\right) / \sigma_{r}$.

Fig. 3. a) Radial stress vs axial pressure. Compaction of $25 \%$ lactose $+75 \%$ smcc at pressure $103 \mathrm{MPa}$. b) Radial stress vs axial pressure. Compaction of $50 \%$ lactose $+50 \%$ smcc at pressure $109 \mathrm{MPa}$. c) Radial stress vs axial pressure. Compaction of $75 \%$ lactose+ $25 \%$ smcc at $P=111 \mathrm{MPa}$. 
a)

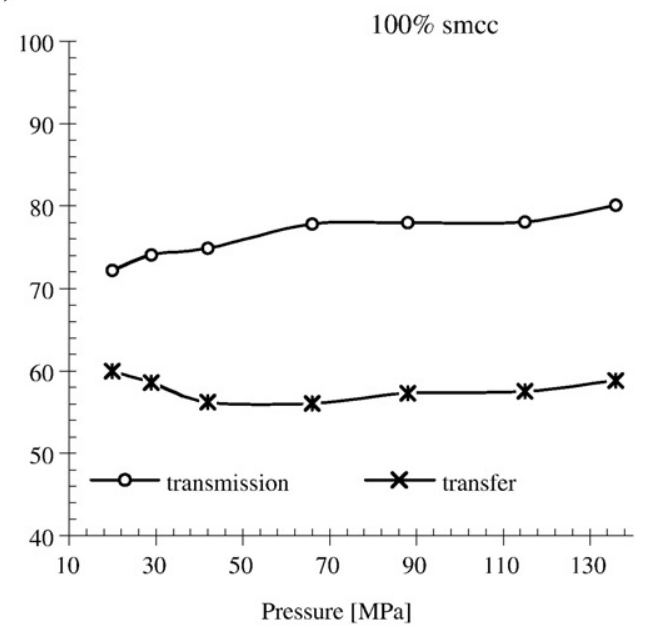

c)

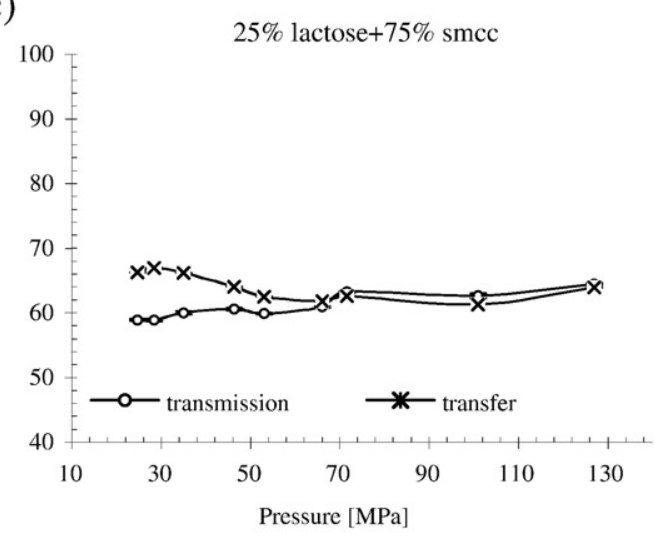

e)

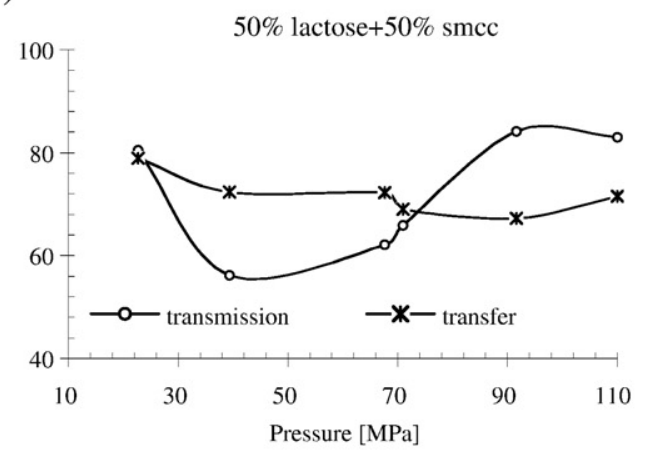

g)

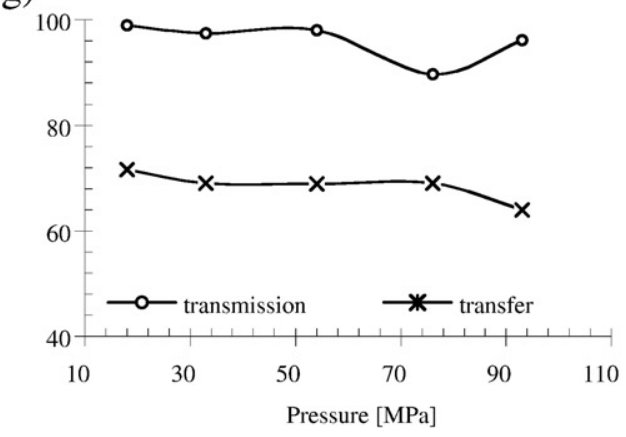

b)

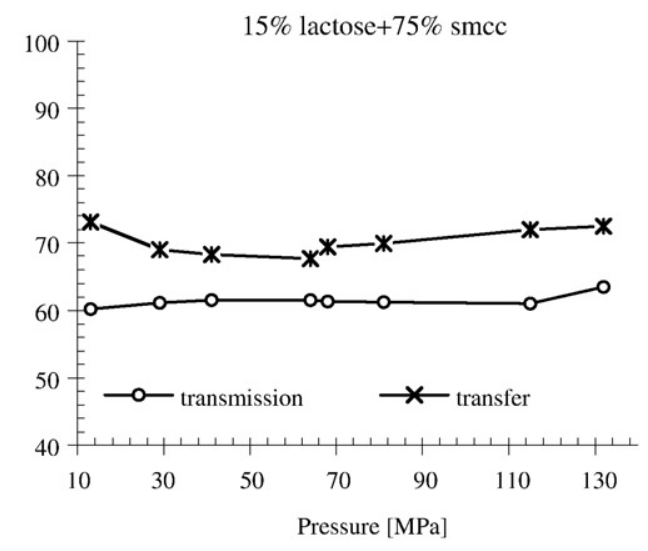

d)

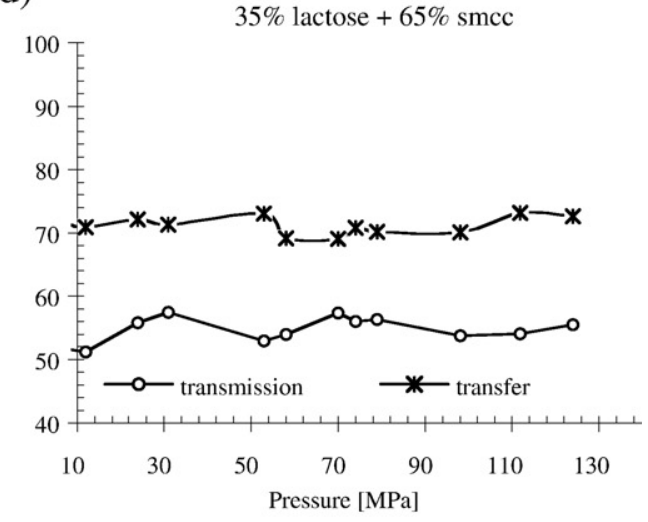

f)

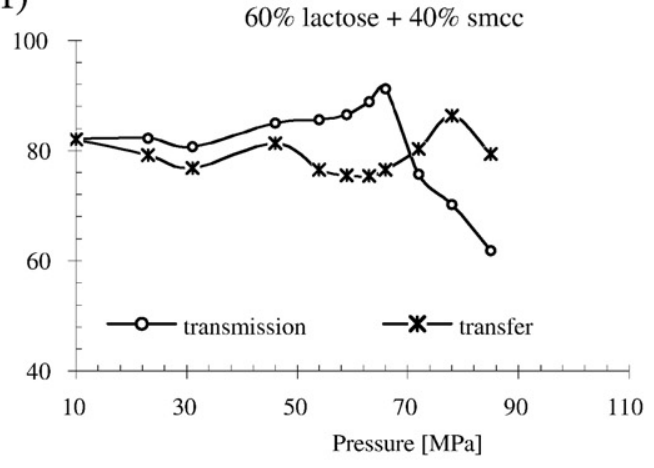

Fig. 4. a) Transfer and transmission ratios versus pressure ( $0 \%$ lactose). b) Transfer and transmission vs pressure (15\% lactose). c) Transfer and transmission vs pressure ( $25 \%$ lactose). d) Transfer and transmission vs pressure (35\% lactose). e) Transfer and transmission vs pressure (50\% lactose). f) Transfer and transmission vs pressure (60\% lactose). g) Transfer and transmission vs pressure (75\% lactose). 
The analysis of die-wall friction from Eq. (3) was complementary to information obtained from the above indices on the behavior of mixtures.

\section{Results and discussions}

\subsection{Radial vs axial pressure}

In Fig. 3(a-c) are plotted the evolution of the radial stress versus the applied pressure for the composition 25,50 and $75 \%$ of lactose during the loading and the unloading steps. The maximum pressure was respectively 103,109 and $111 \mathrm{MPa}$. In the loading phase, the radial and axial pressure profiles were linear. The slope of curve was 0.6 (resp. 0.68 ) for the composition $25 \%$ of lactose (resp. 50 and $75 \%$ of lactose). In the decompression step and after the release of the pressure the tablet remained in the die under an appreciable residual radial stress $\left(\left(\sigma_{\mathrm{r} 1}=15 \mathrm{MPa}\right.\right.$ for mixture with $25 \%$ of lactose, $\left(\sigma_{\mathrm{r}, 1}=\right.$ $20 \mathrm{MPa}$ for mixtures with 50 and $75 \%$ of lactose). According to these values, the residual radial stress could not explain the capping observed in tablets with lactose compositions higher than $50 \%$. As the tablet was yielding continuously in shear during the short time between the release of the pressure and the ejection steps, the Restituted Radial Stress (RRS) from the Eq. (3) was used as an alternative to explain the capping observed for composition with lactose higher than 50\%. In Table 2 are reported, values of RRS according to the composition. As it can be seen two groups may be distinguished: a group with RRS between 2 and $2.6 \%$ for mixtures of lactose lower $50 \%$ and a group with RRS between 5.4 and $5.7 \%$ for compositions with more than $50 \%$ of lactose: "The greater the RRS and the weaker the tablet is weak, more is capping potentially possible". The RRS could be used as criteria of capping if the fracture limit of tablet under shear could be characterized.

\subsection{Densification behavior of binary mixtures}

The behavior of binary mixtures in compaction was analyzed using the stress transmission (Eq. (1)) and stress transfer (Eq. (2)). During die-compaction, the evolution of these ratios was simultaneously represented in Fig. 4(a-g) according to the axial pressure for composition $0,15,25,35,50,65$ and $75 \%$ of lactose. In the case of the single powder compaction of smcc (Fig. 4a), the transmission was typically $76 \%$ whereas the transfer ratio was lower than the transmission and reached $60 \%$.

The addition lactose powder in the mixture in proportions lower than $50 \%$, (Fig. 4(b-d)) show the opposite situation with the transfer higher than the transmission, i.e. the densification seems more oriented out of the axial axis. The case of mixture $50-50 \%$ in Fig. $4 \mathrm{e}$ shows two steps according to the pressure level: for pressure $<70 \mathrm{MPa}$, the stress transfer decreased and was higher than the stress transmission which increased. However, for pressure $>70 \mathrm{MPa}$, the situation was inversed. This change was also found in the evolution of wall friction (Fig. 5b) where the friction coefficient decreased rapidly at $70 \mathrm{MPa}$ meaning the change of properties of the contact. Probably for this composition and around $70 \mathrm{MPa}$, the lactose powder played a lubricant role (by coating contact surface under pressure).

For lactose contents greater than $50 \%$ (Fig. $4 \mathrm{f}-\mathrm{g}$ ), the behavior was reversed and stress transmission was higher than stress transfer resulting from the dominant composition of lactose powder that have a good stress transmission in axial direction.

\subsection{Die-wall friction}

The wall friction coefficient was evaluated using Eq. (4), for the studied mixtures and its evolution with radial pressure is plotted in Fig. 5a for mixtures $0,15,25$ and $35 \%$ of lactose. For smcc alone, the wall friction coefficient was as 0.4 and decreased slightly with radial pressure. a)

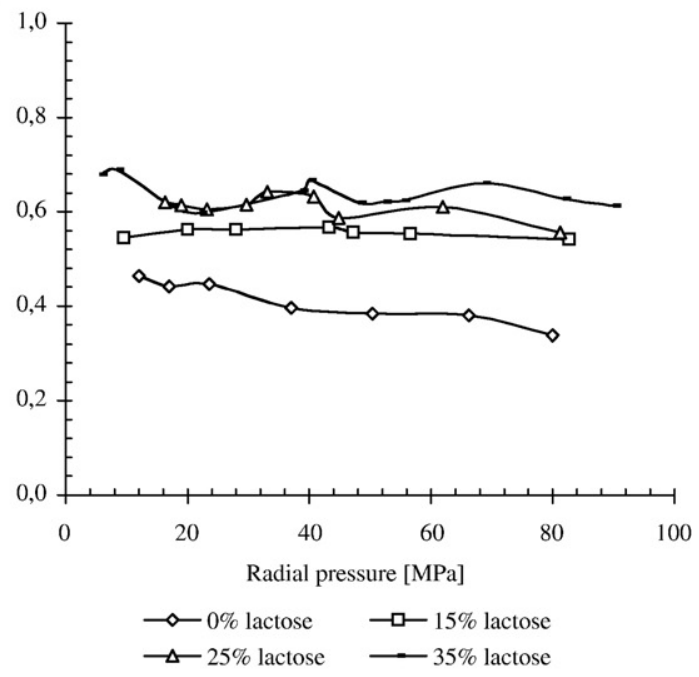

b)

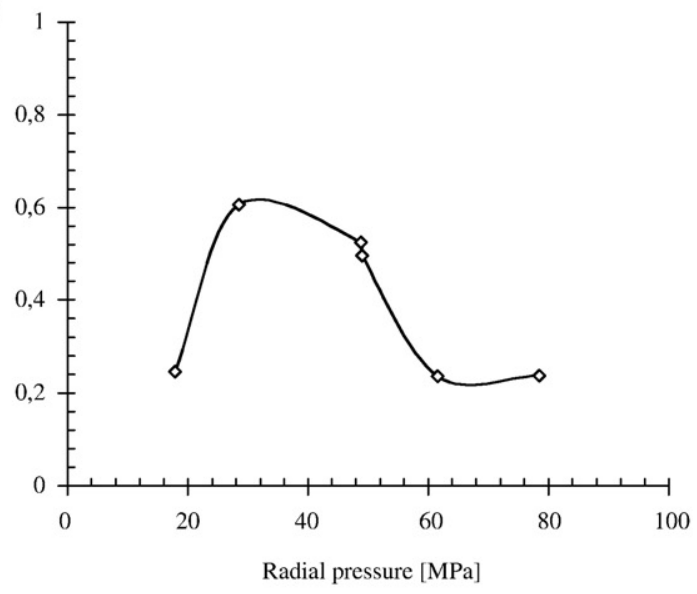

$\rightarrow-50 \%$ lactose

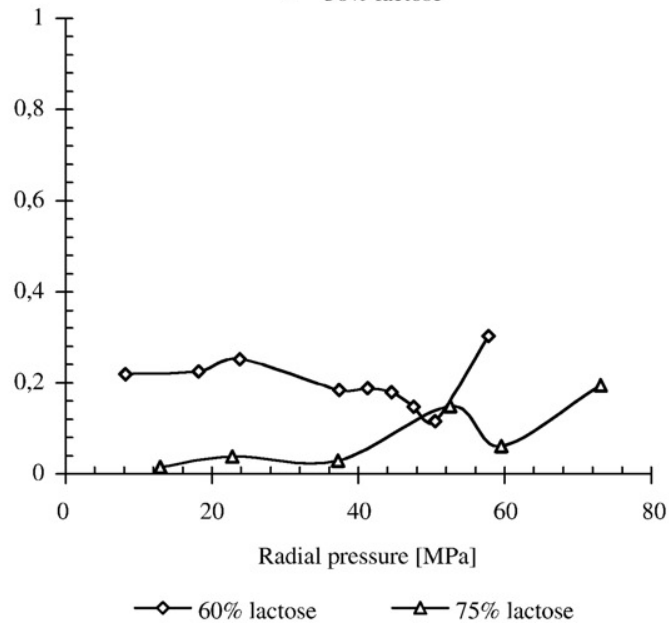

Fig. 5. a) Wall friction vs radial pressure (mixtures with $0,15,25$ and $35 \%$ of lactose) b) Wall friction vs radial pressure (50\% of lactose). c) Wall friction vs radial pressure (mixtures with $60 \%$ and $75 \%$ of lactose).

This value is in agreement with data of other microcrystalline cellulose [14]. It is also shown in Fig. 5a that, the addition of lactose powder to smcc in proportions lower than $50 \%$ increases the friction coefficient due to the high radial pressure generated for such mixtures (stress transfer $\approx 70 \%$ ). On the other hand, for mixtures with lactose compositions greater than $50 \%$ (Fig. $5 \mathrm{c}$ ), the friction coefficient was lower than 0.2 . The 
case of equal compositions (Fig. 5b) showed a transition in the compaction behavior around $70 \mathrm{MPa}$ of applied pressure (50 MPa of radial pressure). Below this pressure, the friction coefficient increased up to 0.61 and decreased rapidly down to 0.2 after. This means a change in the contact properties at the interface between die wall and tablet.

\section{Conclusion}

The densification behavior of binary mixed powders (lactose and a functional excipient containing $98 \%$ of microcrystalline cellulose and $2 \%$ of silica) during die-compaction is analyzed from measurements obtained with an instrumented press equipped with radial gauge. Indices such as stress transfer, stress transmission and wall friction coefficient were analyzed according to the pressure and composition of lactose powder in mixtures. It is shown that there is a change of the densification behavior with the lactose content. High composition ( $>50 \%$ in mass) of lactose in mixtures favors the transmission load in the axial direction, but the resulting tablets have laminations that can be explained from the magnitude of Restituted Radial Stress (RRS) under which tablet is continuously yielding in shear. In the other mixtures with high composition of cellulose favor the compaction in radial direction and present low values of RRS limiting the shearing solicitations after the release of pressure and before ejection. The compaction of a 50:50 mixture shows the role of the pressure in the change of the densification behavior particularly by modifying interfacial properties between tablet and die wall. The analysis proposed here on the densification of binary mixtures could be also employed for the selection of excipients for formulation step.

\section{List of symbols}

\section{$\sigma_{\mathrm{u}}$}

$\sigma_{1}$

$\sigma_{\mathrm{r}}$

$\sigma_{\mathrm{r}, 1}$

\section{$\sigma_{\mathrm{r}, 2}$}

$\mathrm{RRS}=\left(\sigma_{\mathrm{r}, 1}-\sigma_{\mathrm{r}, 2}\right) / \sigma_{\mathrm{u}}$

$\mu\left(\sigma_{\mathrm{r}}\right) \approx\left(\sigma_{\mathrm{u}}-\sigma_{\mathrm{l}}\right) / \sigma_{\mathrm{r}}$ $\sigma_{\mathrm{l}} / \sigma_{\mathrm{u}}$

$\sigma_{\mathrm{r}} / \sigma_{\mathrm{u}}$

Stress transmission ratio

Stress transfer ratio

\section{References}

[1] J.-C. Masteau, G. Thomas, Evolution and modelling of compacted binary mixture porosity. Application to pharmaceutical tablets, J. Chim. Phys. 96 (7) (1999) 1245-1268.

[2] H. Leuenberger, Compression of binary powder mixtures and solubility parameters of solids, Int. J. Pharm. 27 (1985) 127-138.

[3] N. Ramirez, L.M. Melgoza, M. Kuentz, H. Sandoval, I. Caraballo, Comparison of different mathematical models for tensile strength-relative density profiles of binary tablets, Eur. J. Pharm. Sci. 22 (2004) 19-23.

[4] C.-Y. Wu, S.M. Best, A.C. Bentham, B.C. Hancock, W. Bonfield, A simple predictive model for the tensile strength of binary tablets, Eur. J. Pharm. Sci. 25 (2-3) (2005) 331-336.

[5] A. Michrafy, M. Michrafy, M.S. Kadiri, J.A. Dodds, Predictions of tensile strength of binary tablets using linear and power law mixing rules, Int. J. Pharm. 333 (2007) 118-126.

[6] V. Busignies, B. Leclerc, P. Porion, P. Evesque, G. Couarraze, P. Tchoreloff, Compaction behaviour and new predictive approach to the compressibility of binary mixtures of pharmaceutical excipients, Eur. J. Pharm. Biopharm. 64 (2006) 66-74.

[7] B.E. Sherwood, J.W. Becker, A new class of high functionality excipients: silicified microcrystalline cellulose, Pharm. Technol. 10 (October 1998) 78-99.

[8] J.H. Shaxby, J.C. Evans, Trans. Faraday Soc. 19 (1923) 60

[9] H. Unckel, Arch. Eisenhutt Wes. 18 (1945) 161.

[10] H.L. Toor, S.D. Eagleton, Ind. Eng. Chem. 48 (1956) 825.

[11] W.M. Long, Radial pressures in powder compaction, Powder Metall. 6 (1960) 73.

[12] S. Leight, J.E. Carless, B.W. Burt, Compression characteristics of some pharmaceutical materials, J. Pharm. Sci. 56 (1967) 888-892.

[13] K. Sugimori, S. Mori, Characterization of die wall pressure to predict capping of flat or convex-faced drug tablets of various sizes, Powder Technol. 58 (1989) 259-264.

[14] A. Michrafy, M.S. Kadiri, J.A. Dodds, Wall friction and its effects on the density distribution in the compaction of pharmaceutical excipients, Trans. IchemE 81 (2003) 946-951 (Part A) 